\title{
Immediate effect of self-myofascial release on hamstring flexibility
}

\author{
Jihye Jung ${ }^{a}$, Wonjae Choi ${ }^{b}$, Yonghyuk Lee ${ }^{c}$, Jiwoo Kim ${ }^{c}$, Hyunju Kim ${ }^{c}$, Kyoungho Lee ${ }^{c}$, Jaewoo Lee ${ }^{c}$, \\ Seungwon Lee ${ }^{c, d}$ \\ ${ }^{\text {a} P h y s i c a l ~ T h e r a p y ~ T e a m, ~ H a n g e o l e u m ~ R e h a b i l i t a t i o n ~ H o s p i t a l, ~ S e o u l, ~ R e p u b l i c ~ o f ~ K o r e a ~}$ \\ ${ }^{b}$ Department of Physical Therapy, Health and Welfare Graduate School, Seoul, Republic of Korea \\ 'Department of Physical Therapy, College of Health Science and Social Welfare, Sahmyook University, Seoul, Republic of Korea \\ dinstitute of Rehabilitation Science, Sahmyook University, Seoul, Republic of Korea
}

Objective: This study aimed to identify the area with greatest effect using self-myofascial release technique (self-MFR) in the hamstring, suboccipital, and plantar regions.

Design: Cross-sectional study.

Methods: Twenty-two adult subjects were evaluated for flexibility and hamstring pain threshold after self-MFR. Based on the superficial back line, the self-MFR application areas were the suboccipital region, hamstring, and plantar regions. Self-MFR was applied to each area using a wooden pole for a total of 4 minutes. Self-MFR was applied for 3 days at the same time of day, which was randomly assigned for each subject. Treatment was applied to one area each day. The sit and reach test (SRT), active range of motion (AROM), and passive ROM (PROM) were used to determine changes in flexibility, and an algometer was used to determine pain threshold. Pre/post-self-MFR effectiveness was tested using a paired t-test. Repeated measurement was used to compare self-MFR effects in the suboccipital, hamstring, and plantar regions.

Results: When the self-MFR technique was applied to the 3 areas, the SRT showed significant improvement over baseline $(p<0.05)$. Bilateral AROM and PROM showed significant improvements $(p<0.05)$. When the self-MFR technique was applied to the hamstring, the semimembranosus showed a significant change in pain threshold $(p<0.05)$.

Conclusions: Our findings suggest that indirect application based on the Anatomy Trains could be effective for those who need to improve muscle flexibility. Moreover, self-MFR easily alleviates myofascial pain while maintaining flexibility, and can be performed at any time and place.

Key Words: Fascia, Hamstring muscle, Pliability

\section{Introduction}

Myofascial release (MFR) is one of the commonly utilized manual techniques to facilitate the stretching of corresponding tissue continuously or enhance the extensibility of soft tissue through compression while restoring restricted fascia or normal muscular length [1]. MFR is generally to apply slow and continued pressure to restricted fascial layers for 120 to 300 seconds [2]. Self-MFR is a type of MFR im- plemented by each individual using a tool instead of therapist [3]. Self-MFR is an affordable and easily available method to help patients ease their muscular and fascia pain and maintain flexibility [4]. One of the most common instruments for self-MFR is foam roller [5-8] and roller massage [9-13]. Self-MFR increases flexibility, reduces delayed onset muscle soreness [14], adjusts arterial function and hemangioendothelial function [15], and adjusts autonomic nervous system [16] on the continuous basis.

Received: 28, February, 2017 Revised: 17 March, 2017 Accepted: 21 March, 2017

Department of Physical Therapy, College of Health Science and Social Welfare, Sahmyook University, 815 Hwarang-ro, Nowon-gu, Seoul 01795, Republic of Korea Tel: 82-2-3399-1630 Fax: 82-2-3399-1639 E-mail: swlee@syu.ac.kr

(c) This is an Open-Access article distributed under the terms of the Creative Commons Attribution Non-Commercial License (http://creativecommons.org/licens es/by-nc/4.0) which permits unrestricted non-commercial use, distribution, and reproduction in any medium, provided the original work is properly cited.

Copyright $@ 2017$ Korean Academy of Physical Therapy Rehabilitation Science 
Hamstring muscle is a two joint muscle spanning both hip joint and knee joints, functioning as a major muscle for hip extension, knee flexion, and pelvic posterior tilt movement [17]. In ambulation, hamstring reduces velocity of knee extension to prevent hip and knee joint damage while providing dynamic stability. Interaction with hamstring provides correct knee movement and stability. Also in the dynamic movement of sagittal plane abduction and adduction, hamstring muscle provides stability [18] to affect postural balance [19]. The muscular strength ratio to quadriceps and hamstring plays an important role in hip and knee joint stability as well. In addition, hamstring flexibility is important to maintain full range of motion (ROM) of joint and musculoskeletal function while preventing damages [20]. Once flexibility decreases, risks of muscular and postural imbalance grows higher along with the risk of muscular sprain $[21,22]$. Of the hamstring, bicepsfemoris muscle is firmly connected to sacrotuberous ligament and stretched into femoris longus fascia. So, if there is any muscle tightness, movement performance ability would decrease and even low back pain could be caused [23].

In Myers “anatomy train” [24], fascia connected from plantar fascia to epicranial fascia is called as superficial back line (SBL). Based on the SBL, to enhance hamstring flexibility; studies have examined its effect by applying to suboccipital region [25], hamstrings [9,26], and plantar region of the feet [12]. As a result, it was found that muscle tone could decrease indirectly even without directly adjusting hamstrings.

When suboccipital muscle inhibition and self-MFR are applied to suboccipital region, hamstring flexibility instantly increased in self-MFR group [25]. Kim et al. [26], in their study, directly applied to hamstring and found significant change in flexibility as well as muscle strength related to the interaction between quadriceps and hamstring and knee joint ROM. Grieve et al. [12], in their study, applied to plantar region of the feet for hamstring and lumbar spine flexibility and proved its effectiveness.

Based on SBL, preceding study applied self-MFR to each body area and found effectiveness in all of them. But no study has applied the method to three areas to compare the effectiveness of each of them. Also, to choose the area with largest effectiveness under self-MFR on hamstring; these three areas will need to be directly compared for their effect of application. The main purpose of this study is to investigate instant effect on hamstring flexibility increase by applying self-MFR to three areas (suboccipital region, ham- string, and plantar region).

\section{Methods}

\section{Subjects}

For this study, 60 participants were recruited through a 2-week verbal promotion among adult women and men enrolled at Sahmyook Universy in Nowon-gu, Seoul, Korea. Of these, 30 consented to the study after learning the purpose, significance, and methodology. Among the 30 participants, those scoring less than 4 points of 9 points on the Beighton score were selected [27] for this study. The Beighton score evaluates hypermobility of selected joints. It is a widely used tool with high validity [12]. Of the 30 subjects, 5 scored greater than 4 points, and were excluded from this study. Those with low joint mobility, metabolic disease, incomplete post-fracture bone fusion, acute joint pain with exercise or muscle extension, and inflammation around tissues were excluded. All protocols and procedures were approved by the Institutional Review Board of Sahmyook University, and all subjects signed a statement of informed consent before the study began.

\section{Procedure}

This study had a cross-sectional design. To determine the effectiveness of self-MFR, data on 25 subjects meeting the selection criteria were collected. All subjects wore stretchable and loose-fitting pants that did not affect ROM. Preliminary testing included the sit and reach test (SRT), hip joint passive and active ROM in supine position, and assessment of hamstring pain-pressure thresholds (PPTs). To decrease the carry-over effect of each area (suboccipital, hamstring, and plantar regions), self-MFR was applied for 3 days at the same time of day at 24-hour intervals. The application area was randomly chosen for each subject, and self-MFR was applied to one of the areas each day. During the intervention, 3 subjects complained of musculoskeletal pain and were excluded from the experiment. The remaining 22 subjects completed this study, and were assessed for SRT performance, hip joint active ROM (AROM) and passive ROM (PROM), and hamstring flexibility in the same manner as in the posttest.

Self-MFR was applied as follows (Figure 1). (1) For the suboccipital region, subjects were comfortably supine. A wooden pole (diameter $8 \mathrm{~cm}$, length $40 \mathrm{~cm}$ ) was placed under the area, and the head was slowly and gently turned to the left and right for 4 minutes. (2) For the hamstrings, the 

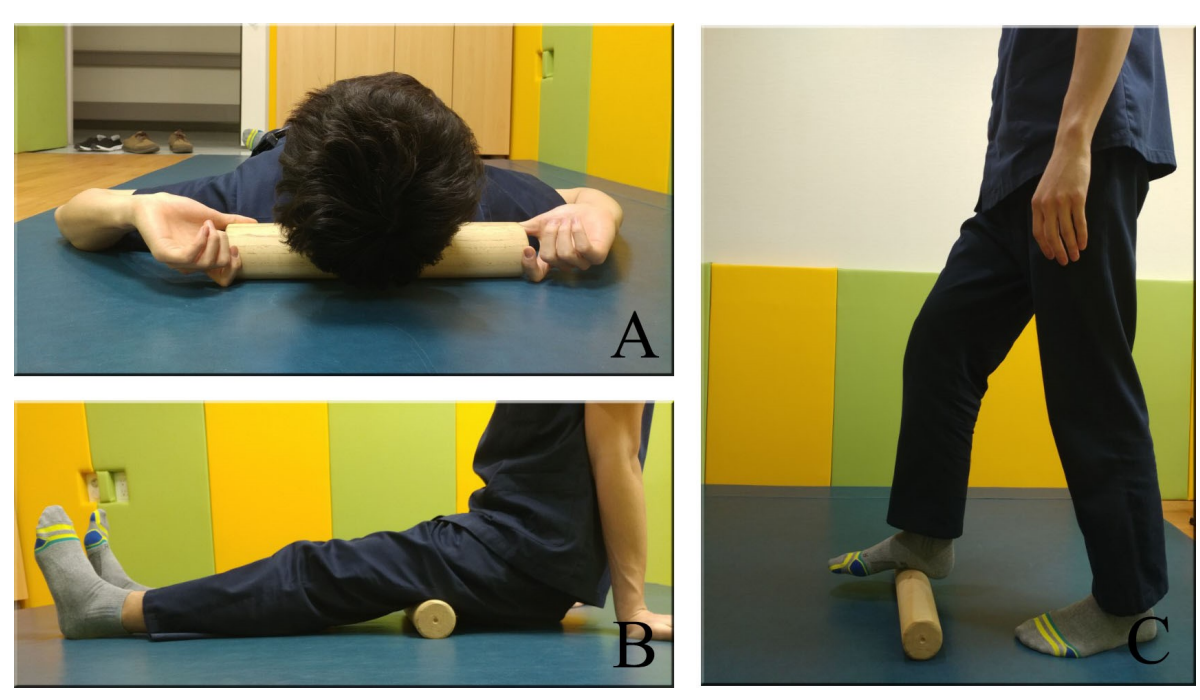

Figure 1. Three types of self-myofacial release. (A) Suboccipital region. (B) Hamstring region. (C) Plantar region. subjects assumed a long sitting position on a firm and even surface by placing the arms backward and loading body weight on the palms. A wooden pole was placed under the hamstrings and slowly moved back and forth from the ischial tuberosity to the popliteus, by applying pressure for 4 minutes. (3) For the plantar region, the subjects stood in front of a 1-m-high support. A wooden pole was placed under the sole, and centered on the metatarsals and inner side of the heel, with support from the other limb. The pole was rolled back and forth slowly for 2 minutes on each side by applying pressure, with a total application time of 4 minutes [12].

\section{Outcome measure}

Hamstring flexibility was assessed using the SRT. In the SRT, subjects take a long sitting position with bare feet on a firm and even surface; the ankles are placed together at $90^{\circ}$ of dorsiflexion in a standard sit and reach box $(30.5 \mathrm{~cm})$; the hands are placed alongside the legs; the subject slowly bends forward along a ruler to the maximum extent possible without low back pain. The maximum bent-forward position is maintained for 2 seconds [27]. At the same time, based on a medial-lateral axis passing through the femoral head, the pelvis should rotate forward on the femur, and the neck and lower back should also bend forward [28]. When the subjects maintained this position, the distance of ruler movement at the edge of the box surface was measured. The test was implemented 3 times and the results were averaged and recorded. The ruler is $35-\mathrm{cm}$ long and is placed parallel to the toe tips. The equipment can measure from $0 \mathrm{~cm}$ (very low flexibility) to $50 \mathrm{~cm}$ (very high flexibility) [29,30]. The
SRT method had an intraclass correlation coefficient of 0.96 [9].

Change in AROM was measured using the straight-leg raising (SLR) test. Subjects were supine and flat on a firm and even surface, straightened their knees, and bent one hip joint through the end of its range. A goniometer was used to record the hip joint angle. The same process was followed on the other leg [31]. Unlike SRT, this method measures hamstring flexibility with the neck and lower back fixed. In the same position, the hip joint passive ROM was also measured. The test-retest reliability was as high as $\mathrm{r}=0.71$ [32].

Hamstring PPTs were assessed with an electronic algometer (Jtech Medical, Midvale, UT, USA) applied to the trigger points of the semitendinosus (ST), semimembranosus ( $\mathrm{SM}$ ), and biceps femoris $(\mathrm{BF})$. The $\mathrm{ST}, \mathrm{SM}$, and $\mathrm{BF}$ trigger points were treated with palpation by referring to a prior study [33]. Measurement was performed by a skilled evaluator with experience using an algometer. The evaluator identified a trigger point, applied pressure perpendicularly, and increased pressure at a rate of $1 \mathrm{~kg} / \mathrm{s}$. Subjects were instructed to say "now" when they felt pain or discomfort. The process was repeated 3 times and average values were recorded [34]. The inter-rater reliability for the pain threshold, digital pressure gauge was 0.75 or greater [35].

\section{Statistical analysis}

IBM SPSS statistics ver. 19.0 (IBM Co., Armonk, NY, USA) was employed for data analysis. Descriptive statistics were used to analyze subject general characteristics. Pre/post self-MFR effectiveness was tested using a paired 
t-test. Repeated measurement was used to compare self-MFR effects in the suboccipital, hamstring, and plantar regions. Statistical significance was set at 0.05 .

\section{Results}

This study had 22 subjects (male, 14; female, 8) who met the selection criteria. The male subjects had an average age of 22.93 years, height of $174.64 \mathrm{~cm}$, and body weight of $70.57 \mathrm{~kg}$. The female subjects had an average age of 21.13 years, height of $162.63 \mathrm{~cm}$, and body weight of $53.00 \mathrm{~kg}$ (Table 1).

When self-MFR technique was applied to the suboccipital, hamstring, and plantar regions, the SRT showed significant improvement $(p<0.05)$. Hip joint AROM and PROM also showed significant increases $(p<0.05)$. The pain pressure threshold only changed significantly in the semimembranosus, when self-MFR was applied to the hamstring $(\mathrm{F}=3.511, p<0.05)$.

\section{Discussion}

In this study, self-MFR was applied to 3 areas (suboccipital, hamstring, and plantar regions), and all induced significant improvement in hamstring flexibility $(p<0.05)$ (Tables 2, 3). This finding is consistent with that of a preceding study, in which self-MFR application to each area affected hamstring flexibility $[9,11,12,25,26]$. Cho et al. [25] reported that self-MFR applied to the suboccipital region significantly increased hamstring flexibility by about $9 \%$, as measured by the SLR test $(p<0.05)$. In this study, AROM and PROM measured by the SLR test were significantly improved after self-MFR was applied at the occipital region. Hip joint AROM increased by $3.75 \%$ on the right and $8.71 \%$ on the left, and PROM increased by $5.86 \%$ on the right and $9.69 \%$ on the left. A study in which MFR was applied by roller massage directly to the hamstring re-

Table 1. General characteristics of participants

$(\mathrm{N}=22)$

\begin{tabular}{lrr}
\hline \multirow{2}{*}{ Demographic } & \multicolumn{2}{c}{ Self-MFR } \\
\cline { 2 - 3 } & \multicolumn{1}{c}{ Male $(\mathrm{n}=14)$} & \multicolumn{1}{c}{ Female $(\mathrm{n}=8)$} \\
\hline Age $(\mathrm{yr})$ & $22.93(1.94)$ & $21.13(0.64)$ \\
Body weight $(\mathrm{kg})$ & $70.57(8.97)$ & $53.00(6.05)$ \\
Height $(\mathrm{cm})$ & $174.64(5.27)$ & $162.63(5.13)$ \\
\hline
\end{tabular}

Values are presented as mean (SD).

MFR: myofascial release.

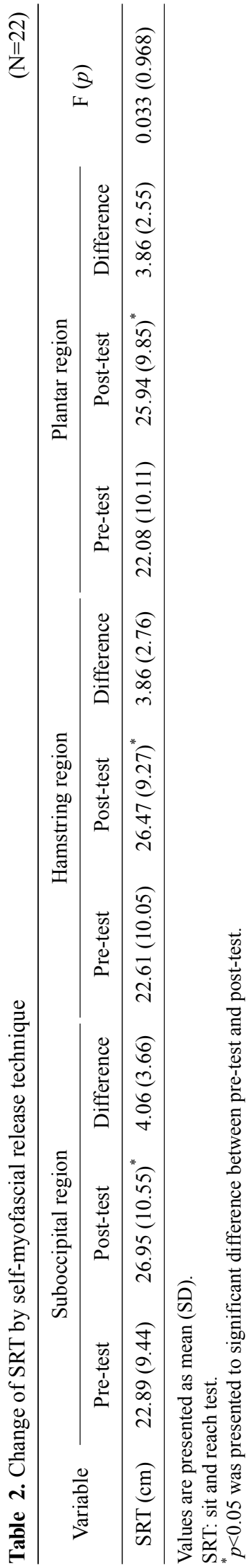



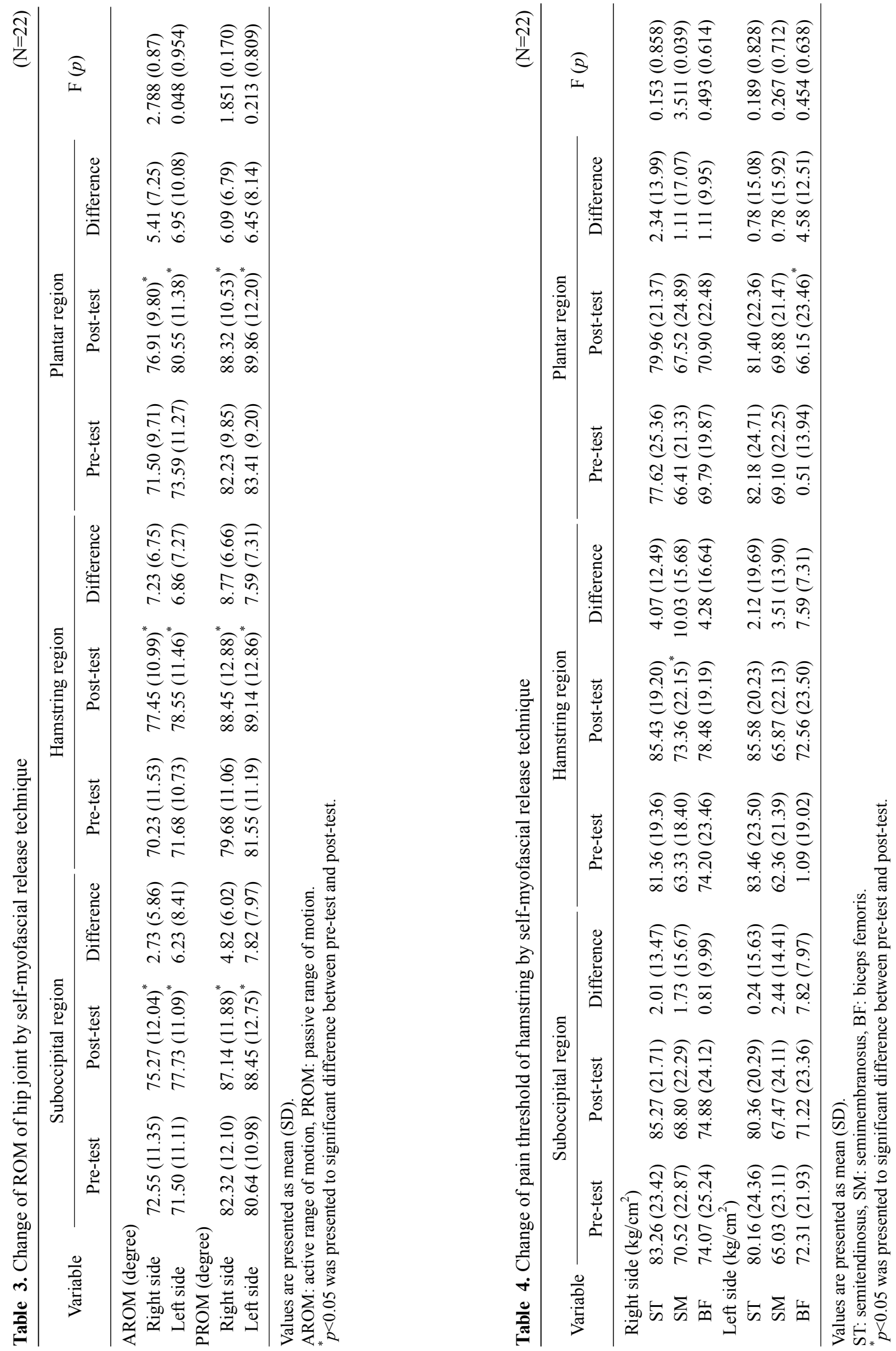
gion improved hip joint ROM $(p<0.05)$ by $4.3 \%$ [9]; as in a previous study, right hip joint AROM (10.28\%) and PROM (11.01\%), and left hip joint AROM (9.58\%) and PROM $(9.31 \%)$ were also increased in our study $(p<0.05)$. Grieve $e t$ $a l$. [12] reported that the sit and reach test (SRT) measurement was significantly increased when self-MFR was applied to the plantar region ( $\mathrm{p}=0.03$ ). We also observed an increase in SRT by $9.52 \%$ when self-MFR was applied to the plantar region, for the same duration as in a previous study $(p<0.05)$.

We used the SRT to measure hamstring flexibility. In previous studies, SRT was reportedly correlated with lumbar spine flexibility; based on studies [27,29] suggesting that pelvic angle measurement was able to assess hamstring flexibility, we measured AROM and PROM of the hip joint using the SLR test position. When self-MFR was applied to the suboccipital, hamstring, and plantar regions, SRT and hip joint AROM and PROM showed significant improvements. This suggests that self-MFR can increase hamstring flexibility when applied to 3 sites.

Application of self-MFR to each area showed significant changes in hamstring flexibility, based on SRT and ROM measurement. This may be associated with the SBL effect of the Anatomy Trains suggested by Myers [24]. Several studies applied interventions to the SBL. Webb and Rajendran [36] reported in systemic review by each indicate that MFR reduces hamstring pain and increases joint ROM. Hyong and Kang also found that passive hamstring stretching was effective in improving cervical ROM and balance ability [37].

The PPT only decreased in the hamstring area (Table 4). A significant change in the hamstring pain threshold was only found in the right SM when self-MFR was applied directly to the hamstring. This may be because most subjects were right-side dominant, and could not apply as much force on the left side during self-MFR; moreover, since they performed self-MFR, they could not properly release the entire hamstring when rolling the wooden pole.

This study found that the same degree of effectiveness could be achieved by applying self-MFR to the back of the head and soles as an alternative, when self-MFR could not be used directly due to hamstring inflammation, skin damage, scarring, etc. This implies that indirect application based on the Anatomy Trains by Myers could be effective for those who need to improve muscle flexibility. Moreover, self-MFR easily alleviates myofascial pain while maintaining flexibility, and can be performed at any time and place.
Thus, it is easily available and applicable [4].

Hamstring tightness causes pelvic posterior tilting and postural imbalance. Consistent use of self-MFR can help maintain hamstring flexibility. Self-MFR can be used by busy individuals and only requires a simple tool. Hamstring tightness or shortening occurs in those with a sedentary lifestyle or inadequate exercise. Self-MFR could prevent and treat hamstring disorders.

A limitation of this study was that the total time for self-MFR was equal for each region. Although the application time was different within each region, the result was meaningful, because a previous study showed sufficient efficacy. Moreover, during self-MFR on the hamstring, the subjects may not have properly adjusted the amount of pressure. In some cases, subjects excessively tensed the supporting upper limb. Thus, they might have had greater difficulty maintaining position than when the occipital or plantar regions were treated with the subjects supine or standing, respectively.

\section{Conflict of Interest}

The authors declared no potential conflicts of interest with respect to the authorship and/or publication of this article.

\section{References}

1. Wong KK, Chai HM, Chen YJ, Wang CL, Shau YW, Wang SF. Mechanical deformation of posterior thoracolumbar fascia after myofascial release in healthy men: a study of dynamic ultrasound imaging. Musculoskelet Sci Pract 2017;27:124-30.

2. Ajimsha MS, Al-Mudahka NR, Al-Madzhar JA. Effectiveness of myofascial release: systematic review of randomized controlled trials. J Bodyw Mov Ther 2015;19:102-12.

3. Beardsley C, Škarabot J. Effects of self-myofascial release: a systematic review. J Bodyw Mov Ther 2015;19:747-58.

4. Kalichman L, Ben David C. Effect of self-myofascial release on myofascial pain, muscle flexibility, and strength: a narrative review. J Bodyw Mov Ther 2016. doi: 10.1016/j.jbmt.2016. 11.006 .

5. MacDonald GZ, Penney MD, Mullaley ME, Cuconato AL, Drake CD, Behm DG, et al. An acute bout of self-myofascial release increases range of motion without a subsequent decrease in muscle activation or force. J Strength Cond Res 2013;27:812-21.

6. Mohr AR, Long BC, Goad CL. Effect of foam rolling and static stretching on passive hip-flexion range of motion. J Sport Rehabil 2014;23:296-9.

7. Škarabot J, Beardsley C, Štirn I. Comparing the effects of selfmyofascial release with static stretching on ankle range-of-motion in adolescent athletes. Int J Sports Phys Ther 2015;10:203- 
12.

8. Peacock CA, Krein DD, Antonio J, Sanders GJ, Silver TA, Colas M. Comparing acute bouts of sagittal plane progression foam rolling vs. frontal plane progression foam rolling. J Strength Cond Res 2015;29:2310-5.

9. Sullivan KM, Silvey DB, Button DC, Behm DG. Roller-massager application to the hamstrings increases sit-and-reach range of motion within five to ten seconds without performance impairments. Int J Sports Phys Ther 2013;8:228-36.

10. Bradbury-Squires DJ, Noftall JC, Sullivan KM, Behm DG, Power KE, Button DC. Roller-massager application to the quadriceps and knee-joint range of motion and neuromuscular efficiency during a lunge. J Athl Train 2015;50:133-40.

11. Halperin I, Aboodarda SJ, Button DC, Andersen LL, Behm DG. Roller massager improves range of motion of plantar flexor muscles without subsequent decreases in force parameters. Int $\mathrm{J}$ Sports Phys Ther 2014;9:92-102.

12. Grieve R, Goodwin F, Alfaki M, Bourton AJ, Jeffries C, Scott H. The immediate effect of bilateral self myofascial release on the plantar surface of the feet on hamstring and lumbar spine flexibility: a pilot randomised controlled trial. J Bodyw Mov Ther 2015;19:544-52.

13. Mikesky AE, Bahamonde RE, Stanton K, Alvey T, Fitton T. Acute effects of The Stick on strength, power, and flexibility. J Strength Cond Res 2002;16:446-50.

14. Jay K, Sundstrup E, Søndergaard SD, Behm D, Brandt M, Særvoll CA, et al. Specific and cross over effects of massage for muscle soreness: randomized controlled trial. Int J Sports Phys Ther 2014;9:82-91.

15. Okamoto T, Masuhara M, Ikuta K. Acute effects of self-myofascial release using a foam roller on arterial function. $\mathrm{J}$ Strength Cond Res 2014;28:69-73.

16. Chan YC, Wang TJ, Chang CC, Chen LC, Chu HY, Lin SP, et al. Short-term effects of self-massage combined with home exercise on pain, daily activity, and autonomic function in patients with myofascial pain dysfunction syndrome. J Phys Ther Sci 2015;27: 217-21.

17. Koulouris G, Connell D. Imaging of hamstring injuries: therapeutic implications. Eur Radiol 2006;16:1478-87.

18. Hafez AR, Al-Johani AH, Zakaria AR, Al-Ahaideb A, Buragadda $\mathrm{S}$, Melam GR, et al. Treatment of knee osteoarthritis in relation to hamstring and quadriceps strength. J Phys Ther Sci 2013;25: 1401-5.

19. Jandre Reis FJ, Macedo AR. Influence of hamstring tightness in pelvic, lumbar and trunk range of motion in low back pain and asymptomatic volunteers during forward bending. Asian Spine J 2015;9:535-40.

20. Law RY, Harvey LA, Nicholas MK, Tonkin L, De Sousa M, Finniss DG. Stretch exercises increase tolerance to stretch in patients with chronic musculoskeletal pain: a randomized controlled trial. Phys Ther 2009;89:1016-26.

21. Witvrouw E, Danneels L, Asselman P, D'Have T, Cambier D. Muscle flexibility as a risk factor for developing muscle injuries in male professional soccer players. A prospective study. Am J Sports Med 2003;31:41-6.

22. Bradley PS, Portas MD. The relationship between preseason range of motion and muscle strain injury in elite soccer players. J Strength Cond Res 2007;21:1155-9.
23. Gajdosik RL, Hatcher CK, Whitsell S. Influence of short hamstring muscles on the pelvis and lumbar spine in standing and during the toe-touch test. Clin Biomech (Bristol, Avon) 1992;7: 38-42.

24. Myers TW. Anatomy trains: myofascial meridians for manual and movement therapists. 3rd ed. Edinburgh: Churchill Livingstone Elsevier; 2014.

25. Cho SH, Kim SH, Park DJ. The comparison of the immediate effects of application of the suboccipital muscle inhibition and self-myofascial release techniques in the suboccipital region on short hamstring. J Phys Ther Sci 2015;27:195-7.

26. Kim DH, Matkowskyj KA, Lubner MG, Hinshaw JL, Munoz Del Rio A, Pooler BD, et al. Serrated polyps at CT colonography: prevalence and characteristics of the serrated polyp spectrum. Radiology 2016;280:455-63.

27. Lemmink KA, Kemper HC, de Greef MH, Rispens P, Stevens M. The validity of the sit-and-reach test and the modified sit-andreach test in middle-aged to older men and women. Res Q Exerc Sport 2003;74:331-6.

28. Youdas JW, Krause DA, Hollman JH. Validity of hamstring muscle length assessment during the sit-and-reach test using an inclinometer to measure hip joint angle. J Strength Cond Res 2008; 22:303-9.

29. Cornbleet SL, Woolsey NB. Assessment of hamstring muscle length in school-aged children using the sit-and-reach test and the inclinometer measure of hip joint angle. Phys Ther 1996;76: $850-5$.

30. Hemmatinezhad M, Afsharnezhad T, Nateghi N, Damirchi A. The relationship between limb length with classical and modified back saver sit-and-reach tests in student boys. Int J Fit 2009; $5: 69$.

31. Nussbaumer S, Leunig M, Glatthorn JF, Stauffacher S, Gerber H, Maffiuletti NA. Validity and test-retest reliability of manual goniometers for measuring passive hip range of motion in femoroacetabular impingement patients. BMC Musculoskelet Disord 2010;11:194.

32. Neto T, Jacobsohn L, Carita AI, Oliveira R. Reliability of the active-knee-extension and straight-leg-raise tests in subjects with flexibility deficits. J Sport Rehabil 2015; Technical Notes 17: 2014-0220.

33. Aparicio EQ, Quirante LB, Blanco CR, Sendín FA. Immediate effects of the suboccipital muscle inhibition technique in subjects with short hamstring syndrome. J Manipulative Physiol Ther 2009;32:262-9.

34. Kim JH, Kim JG, Do KS, Yim JG. The effect of applying a head-weight device on cervical angle and pain of neck muscles. Phys Ther Rehabil Sci 2016;5:101-5.

35. Antonaci F, Sand T, Lucas GA. Pressure algometry in healthy subjects: inter-examiner variability. Scand J Rehabil Med 1998; 30:3-8.

36. Webb TR, Rajendran D. Myofascial techniques: what are their effects on joint range of motion and pain? - a systematic review and meta-analysis of randomised controlled trials. J Bodyw Mov Ther 2016;20:682-99.

37. Hyong IH, Kang JH. The immediate effects of passive hamstring stretching exercises on the cervical spine range of motion and balance. J Phys Ther Sci 2013;25:113-6. 